\begin{tabular}{|c|c|c|c|c|c|c|}
\hline \multirow{4}{*}{ Impact Factor: } & ISRA (India) & $=3.117$ & SIS (USA) & $=0.912$ & ICV (Poland) & $=6.630$ \\
\hline & ISI (Dubai, UAE & $=0.829$ & РИНЦ (Russia & $=0.156$ & PIF (India) & $=1.940$ \\
\hline & GIF (Australia) & $=0.564$ & ESJI (KZ) & $=\mathbf{5 . 0 1 5}$ & IBI (India) & $=4.260$ \\
\hline & JIF & $=1.500$ & SJIF (Morocco & $=5.667$ & & \\
\hline
\end{tabular}

\begin{tabular}{|c|c|}
\hline \multicolumn{2}{|c|}{$\begin{array}{l}\text { SOI: } \frac{1.1 / \mathrm{TAS}}{\mathrm{DOI}} \mathrm{10.15863/ \textrm {TAS }} \\
\text { International Scientific Journal } \\
\text { Theoretical \& Applied Science }\end{array}$} \\
\hline p-ISSN: 2308-4944 (print) & e-ISSN: 2409-0085 (online) \\
\hline Year: 2018 & Volume: 68 \\
\hline Published: 30.12 .2018 & Attp://T-Science.org \\
\hline
\end{tabular}

SECTION 13. Geography. History. Oceanology. Meteorology.
QR - Issue

QR - Article
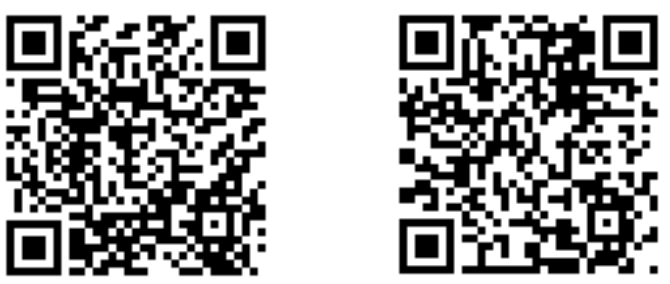

R. Kravchenko

Ph.D., Universidad UTE,

Quito, Ecuador roman.kravchenko@ute.edu.ec

M. Pelaez

Quito, Ecuador

mayreasco@gmail.com

R. Granda

Ph.D., Universidad UTE

Quito, Ecuador

roberto.granda@ute.edu.ec

\title{
COMPARATIVE ANALYSIS OF SLOPE LANDS USED FOR CULTIVATION OF VARIOUS CROPS IN THE COASTAL PART OF THE PROVINCE OF ESMERALDAS, ECUADOR
}

Abstract: This work investigates the erosion-prone lands in the coastal part of Ecuador. Sights with various agricultural crops located on slopes with the same steepness of $8^{\circ}$ are compared. The sectors under study are used for the cultivation of African palm, cocoa and banana crops and pastures. It is established that the highest content of organic matter is contained in the soils on the fields occupied by the African palm - 10.5\%. Also this site has been found to have the highest nitrogen content. Pastures also have a high content of organic matter in the soil - 9.37\%. The lowest percentage of organic matter is found in the soils used for the cultivation of cocoa crops - 3.26\%. The lands of all sectors have a low phosphorus content, and a high concentration of iron and manganese.

Key words: soil, slope, erosion-prone land, crops.

Language: Russian

Citation: Kravchenko, R., Pelaez, M., \& Granda, R. (2018). Comparative analysis of slope lands used for cultivation of various crops in the coastal part of the province of Esmeraldas, Ecuador. ISJ Theoretical \& Applied Science, 12 (68), 312-315.

Soi: http://s-o-i.org/1.1/TAS-12-68-46 Doi: crossef https://dx.doi.org/10.15863/TAS.2018.12.68.46

\section{СРАВНИТЕЛЬНЫЙ АНАЛИЗ СКЛОНОВЫХ ЗЕМЕЛЬ ИСПОЛЬЗУЕМЫХ ДЛЯ ВОЗДЕЛЫВАНИЯ РАЗЛИЧНЫХ СЕЛЬСКОХОЗЯЙСТВЕННЫХ КУЛЬТУР В ПРИБРЕЖНОЙ ЧАСТИ ПРОВИНЦИИ ЭСМЕРАЛЬДАС, ЭКВАДОР}

Аннотация: Исследованы эрозионно опасные земли в прибрежной части Эквадора. Проводилось сравнение участков с различными сельскохозяйственными культурами и расположенных на склонах с одинаковой крутизной в $8^{\circ}$. Изучались сектора, используемые для воздельвания Африканской пальмы, какао и банановых культур, а также пастбища. Установлено, что наибольшее содержание органического вещества отмечено в почвах на полях занятых Африканской пальмой - 10,5 \%. Также для данного участка выльлено наиболее высокое содержание азота. Для пастбищ тоже характерно высокое содержание органического вещества в почве - 9,37\%. Самый низкий процент органического вещества отмечен в почвах, используемых для воздельвания какао-культур - 3,26 \%. На землях всех секторов выявлено низкое содержание фосфора, и высокая концентрация железа и марганца.

Ключевые слова: почва, склон, эрозионно опасные земли, сельскохозяйственные культуры. 


\begin{tabular}{|c|c|c|c|c|c|c|}
\hline \multirow{4}{*}{ Impact Factor: } & ISRA (India) & $=3.117$ & SIS (USA) & $=0.912$ & ICV (Poland) & $=6.630$ \\
\hline & ISI (Dubai, UAE & $=0.829$ & РИНЦ (Russia & $=0.156$ & PIF (India) & $=1.940$ \\
\hline & GIF (Australia) & $=0.564$ & ESJI (KZ) & $=\mathbf{5 . 0 1 5}$ & IBI (India) & $=4.260$ \\
\hline & JIF & $=1.500$ & SJIF (Morocco & $=5.667$ & & \\
\hline
\end{tabular}

\section{Введение.}

Для экономики ряда провинций республики Эквадор значимым является такая отрасль хозяйства как растениеводство. Особенно это важно для административно-территориальных образований, в которых подавляющее большинство составляет сельское население. Разнообразие природных условий страны приводит к необходимости детальной оценки как воздействия сельскохозяйственных культур на деградацию земель, так и подбора наиболее подходящих географических провинций для конкретных растений.

Особенность экваториальных и тропических зон состоит в интенсивных процессах преобразования почв. В ряде случаев эрозионные процессы могут развиваться с очень высокой интенсивностью, выводя из хозяйственной деятельности значительные площади.

Специфике взаимовлияния земель и сельскохозяйственных культур, в том числе с учетом эрозионных процессов в тропических и экваториальных зонах различных районов мира был посвящен ряд исследований [1- 10].

Целью данной работы является сравнительная характеристика эрозионно опасных земель используемых для возделывания различных сельскохозяйственных культур в прибрежной провинции Эквадора.

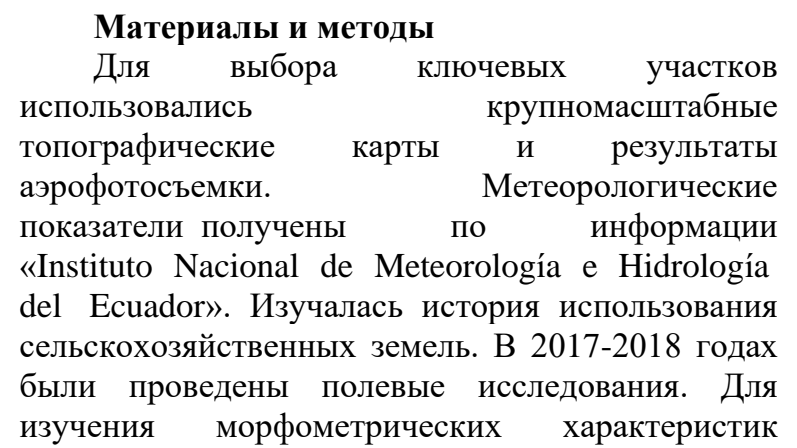

склонов использовался теодолит DGT 10 CSTBERGER/Digital. Проводился отбор почвенных проб. Анализ почвы выполнялся в лаборатории «Agrocalidad», г. Кито.

\section{Результаты и их обсуждение}

Исследование проводилось в Эквадоре на территории провинции Эсмеральдас (Esmeraldas), в прибрежной части кантона Сан Лоренцо (San Lorenzo). Ключевой участок расположен в пределах административно-территориального образования Тулулби (Tululbí), входящего в указанный кантон.

Территория представляет из себя равнину близ Тихоокеанского побережья. Высота над уровнем моря от 10 до 70 метров. Однако наличие склонов разной крутизны создает предпосылки для развития эрозионных процессов. Расположение близ экватора предопределяет основные климатические характеристики. Средняя температуры составляет около $25^{\circ} \mathrm{C}$ и мало меняются по месяцам. Среднегодовое количество осадков превышает 2500 мм. Наиболее дождливым месяцем является январь, минимальное значение осадков отмечается в сентябре. Характерны различия в годовом распределении осадков. Влажный сезон приходится на период с января по июнь-июль. В период с января по апрель количество осадков составляет около 300 мм в месяц. Относительно сухой сезон приходится на период август - декабрь. На изученной территории овражная эрозия проявляется очень незначительно. Отмечаются отдельные неглубокие промоины.

Сравнительный анализ проводился на четырех ключевых участках расположенных на склоне с уклоном $8^{\circ}$. Следует отметить, что данные склоны относятся к эрозионно опасным. Особенно с учетом выраженных сухого и влажного сезонов года. Значительная часть осадков выпадает в виде ливневых дождей.

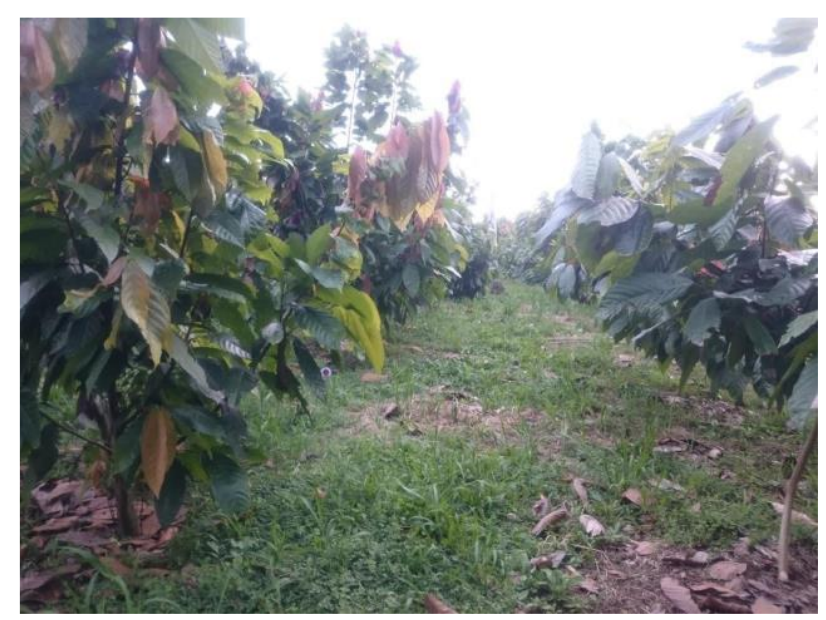

Рисунок 1. Агроэкосистема какао в исследуемом районе. 


\begin{tabular}{|c|c|c|c|c|c|c|}
\hline \multirow{4}{*}{ Impact Factor: } & ISRA (India) & $=3.117$ & SIS (USA) & $=0.912$ & ICV (Poland) & $=6.630$ \\
\hline & ISI (Dubai, UAE & $=0.829$ & РИНЦ (Russia & $=0.156$ & PIF (India) & $=1.940$ \\
\hline & GIF (Australia) & $=0.564$ & ESJI (KZ) & $=\mathbf{5 . 0 1 5}$ & IBI (India) & $=4.260$ \\
\hline & JIF & $=1.500$ & SJIF (Morocco & $=5.667$ & & \\
\hline
\end{tabular}

Каждый исследованный сектор используется $\begin{array}{lrr}\text { для } & \text { возделывания } & \text { различных } \\ \text { сельскохозяйственных культур: } & \text { африканская }\end{array}$ пальма, банановые и какао культуры, пастбища. На рисунках 1 и 2 приведены фотографии агроэкосистем какао и африканской пальмы в изученном районе.

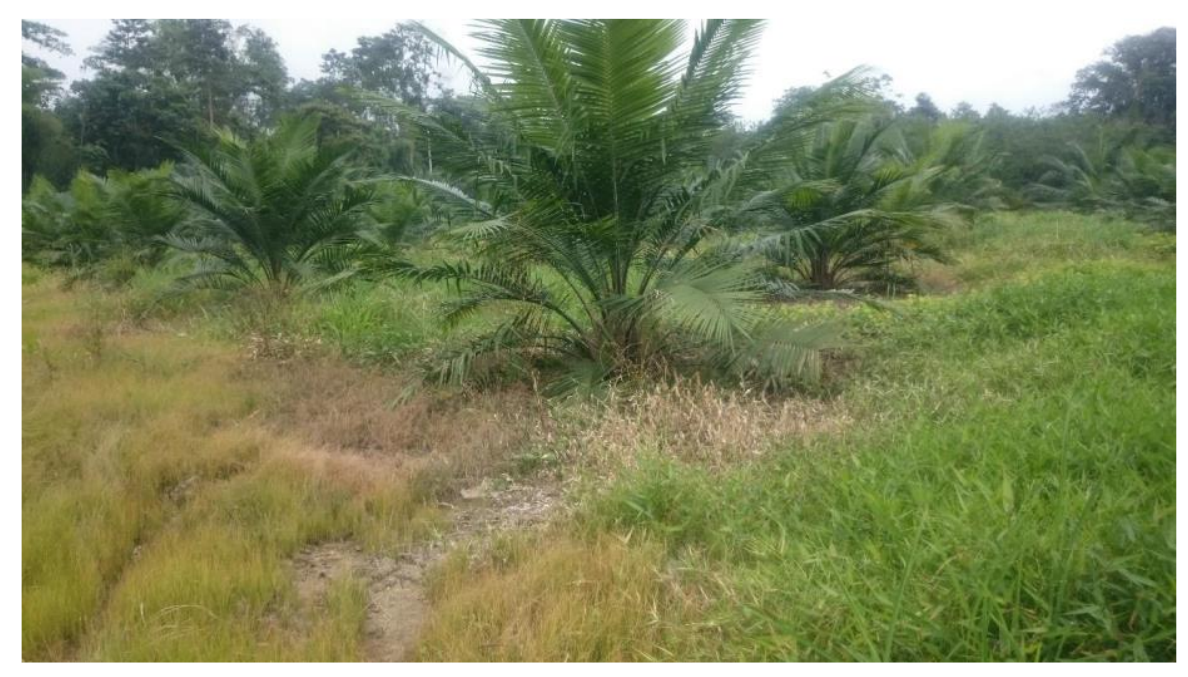

Рисунок 2. Агроэкосистема африканской пальмы в исследуемом районе.

В таблице 1 представлены результаты исследования почв.

Прежде всего обращает на себя внимание различие в содержании органического вещества в почвах на участках занятых различными культурами. Наибольшее содержание отмечено на полях занятых Африканской пальмой (10,5\%). На участках возделывания данной масличной культуры отмечается также наибольшее процентное содержание азота, среди исследованных секторов. Пастбищные почвы также отличаются высоким содержанием органического вещества 9,37\%. Самый низкий процент отмечен в почвах используемых для возделывания какао-культур - 3,26\%. Сравнительной характеристике склонов различной крутизны используемых для выращивания какао была посвящена одна из предыдущих работ авторов [7], где отмечались существенные различия в зависимости от угла наклона поверхности.

$\mathrm{B}$ то же время для пастбищ и полей с африканской пальмой установлено низкое содержание калия, тогда как на двух других секторах - высокое. Также в местах возделывания африканской пальмы отмечается крайне низкое содержание кальция и магния. Почвы кислые. По интерпретации «Agencia Ecuatoriana de Aseguramiento de Calidad Agro» для прибрежной зоны Эквадора почвы всех исследованных участков бедны фосфором, но характеризуются высокой концентрацией марганца, и очень высокой (около $300 \mathrm{mg} / \mathrm{kg}$ и более) железа.

\section{Выводы.}

В исследованных природных условиях земли расположенные на уклонах в $8^{\circ}$ можно отнести к эрозионно опасным. При сравнении почв на участках склона одинаковой крутизны, но с различными сельскохозяйственными культурами выявлены существенные различия. Самый высокий процент органического вещества отмечен в почвах используемых для возделывания африканской пальмы (10,5 \%), самый низкий - на полях с какао культурами $(3,26 \%)$. В почвах очень высокое содержание железа.

Таблица 1. Результаты исследования почв склоновых земель ключевых участков.

\begin{tabular}{|c|c|c|c|c|}
\hline Параметры & $\begin{array}{c}\text { Участок 1 } \\
\text { Какао культуры }\end{array}$ & $\begin{array}{c}\text { Участок 2 } \\
\text { Пастбища }\end{array}$ & $\begin{array}{c}\text { Участок 3 } \\
\text { Африканская } \\
\text { пальма }\end{array}$ & $\begin{array}{c}\text { Участок 4 } \\
\text { Банановые } \\
\text { культуры }\end{array}$ \\
\hline Органическое вещество (\%) & 3,26 & 9,37 & 10,5 & 4,32 \\
\hline
\end{tabular}




\begin{tabular}{|c|c|c|c|c|c|c|}
\hline \multirow{4}{*}{ Impact Factor: } & ISRA (India) & $=\mathbf{3 . 1 1 7}$ & SIS (USA) & $=0.912$ & ICV (Poland) & $=6.630$ \\
\hline & ISI (Dubai, UAE & $=0.829$ & РИНЦ (Russia & $=0.156$ & PIF (India) & $=1.940$ \\
\hline & GIF (Australia) & $=0.564$ & ESJI (KZ) & $=5.015$ & IBI (India) & $=4.260$ \\
\hline & JIF & $=1.500$ & SJIF (Morocco & $=5.667$ & & \\
\hline
\end{tabular}

\begin{tabular}{|l|c|c|c|c|}
\hline Азот (\%) & 0,16 & 0,47 & 0,52 & 0,22 \\
\hline Фосфор $(\mathrm{mg} / \mathrm{kg})$ & 3,5 & 3,5 & 5,8 & 3,5 \\
\hline Калий $(\mathrm{cmol} / \mathrm{kg})$ & 0,55 & 0,13 & 0,1 & 0,56 \\
\hline Кальций $(\mathrm{cmol} / \mathrm{kg})$ & 3,7 & 7,81 & 0,92 & 3,9 \\
\hline Магний $(\mathrm{cmol} / \mathrm{kg})$ & 1,22 & 1,41 & 0,22 & 1,23 \\
\hline Железо $(\mathrm{mg} / \mathrm{kg})$ & 534,2 & 606,4 & 298 & 360,7 \\
\hline Марганец $(\mathrm{mg} / \mathrm{kg})$ & 16,85 & 40,99 & 20,9 & 24,94 \\
\hline Медь $(\mathrm{mg} / \mathrm{kg})$ & 4,7 & 7,36 & 10,44 & 2,96 \\
\hline Цинк $(\mathrm{mg} / \mathrm{kg})$ & 3,11 & 7,04 & 3,83 & 3,21 \\
\hline рН & 5,34 & 5,87 & 4,42 & 5,02 \\
\hline
\end{tabular}

\section{References:}

1. Adeniyi, S. A., Petrus de Clercq, W., \& Adriaan van Niekerk (2017). Development of a composite soil degradation assessment index for cocoa agroecosystems in southwestern Nigeria. Solid Earth, 8, 827-843.

2. Asbur, Y., et al. (2016). The Roles of Asystasia gangetica (L.) T. Anderson and Ridge Terrace in Reducing Soil Erosion and Nutrient Losses in Oil Palm Plantation in South Lampung, Indonesia. Journal of Tropical Crop Science Vol. 3 No. 2, 49-55.

3. Dash, S., Behera, S., Pushpavathi, Y. \& Mishra, K. (2018). Conservation Agriculture Approaches in Banana to Improve Soil Quality and Farm Productivity. International Journal of Current Microbiology and Applied Sciences, Vol. 7(03), 651-658.

4. Gonzales, F., et al. (2018). Soil erosion magnitude of upland farming practices in Bataan. Journal of Soil Science and Environmental Management, Vol. 9(3), 40-46.

5. Guillaume, T., Damris, M., \& Kuzyakov, Y. (2015). Losses of soil carbon by converting tropical forest to plantations: erosion and decomposition estimated by C. Global Change Biology, 21, 3548-3560.
6. Kravchenko, R., \& Flores, M. J. (2017). The characterization of the agricultural lands on the erosion-threatened slopes near Alaquez, Ecuador. Bulletin of Science and Practice, (4), 184-187.

7. Kravchenko, R., Pelaez, M., \& Granda, R. (2018). The estimation of the erosion-threatened lands used for cocoa crops in San Lorenzo canton, Esmeraldas province, Ecuador. Bulletin of Science and Practice, 4(10), 84-87.

8. Li, J., Okin, G., Alvarez, L., \& Epstein, H. (2008). Effects of wind erosion on the spatial heterogeneity of soil nutrients in two desert grassland communities. Biogeochemistry, 88, 73-88.

9. Shat, S., Yusop, Z., Askari, M., \& Ziegler, A. (2016). Estimation of Soil Erosion Rates in Oil Palm Plantation with Different Land Cover. Soft Soil Engineering International Conference. Ser.: Mater. Sci. Eng. 136.

10. Zhu, H., et al. (2015). Reducing soil erosion by improving community functional diversity in semi-arid grasslands. Journal of Applied Ecology, 52, 1063-1072. 